\title{
ARQUEOLOGÍA DEL DOLOR. UN (RE)ENCUENTRO CON PAULO FREIRE E IVÁN ILLICH PARA APRENDER DEL SUFRIMIENTO
}

DOI: 10.48075/ri.v23i1.26709

Miguel Salas Soneira ${ }^{1}$

Asun Pié Balaguer ${ }^{2}$

RESUMEN: El presente texto recupera herramientas para una pedagogía de la liberación y promoción de la intersubjetividad dañada en el campo de la salud mental. Nuestra lectura actualizada de Paulo Freire se articula en diálogo con los aportes de Iván Illich y su posición crítica con la patologización del sufrimiento. Ambos autores nos permiten fundamentar una praxis en el campo de la salud mental que hemos llamado arqueología del dolor. Para ello, en primer lugar, se abordan las relaciones entre opresión y salud mental dando cuenta de la colonización de los cuerpos y las mentes por la vía de la sustracción del saber lego, la psiquiatrización y sobremedicación. En segundo lugar, se abordan las prescripciones y adherencias para comprender qué aspectos de la actuación socioeducativa en salud mental asumen la forma de discursos y prácticas de carácter opresivo y qué claves pedagógicas freirianas se pueden tomar en consideración a efectos de revertir dicha condición. En tercer lugar, se presentan las especificidades de los mitos, discursos y prácticas institucionalizadas que reproducen y mantienen la opresión de los sujetos psiquiatrizados, así como algunas condiciones para su liberación; a saber, la recuperación de la palabra y la construcción simbólica de las propias historias de vida. Finalmente, se expone la experiencia de transformación que está suponiendo el movimiento internacional de Hearing Voices como ejemplo de liberación frente a la opresión biomédica.

\section{ARCHEOLOGY OF PAIN. A RE-ENCOUNTER WITH PAULO FREIRE AND IVAN ILLICH TO LEARN FROM SUFFERING}

ABSTRACT: He present text recovers tools for a pedagogy of release and promotion of the damaged inter-subjectivity in the field of mental health. Our updated reading of Paulo Freire is articulated in dialogue with the contributions of Ivan Illich and his critical position about the pathologization of

\footnotetext{
${ }^{1}$ Es Doctor en Ciencias de la Educación por la Universidad de Barcelona (UB), educador social por la Universidad de Santiago de Compostela (USC) y licenciado en Publicidad y Relaciones Públicas por la Universidad de Vigo (UVIGO). Profesor colaborador en Estudios de Psicología y Ciencias de la Educación, Universitat Oberta de Catalunya (UOC). Email: msalasson@uoc.edu

2 Doctora en pedagogía por la Universidad de Barcelona. Directora del programa de posgrado de Salud Mental Colectiva. Profesora/investigadora de los Estudios de Psicología y Ciencias de la Educación de la Universitat Oberta de Catalunya (UOC). Sus investigaciones se centran en el campo de los Estudios Feministas de la Discapacidad. Email: apieb@uoc.edu
} 
suffering. Both authors allow us to base a praxis on the field of mental health that we called the archeology of pain. To this end, the relationships between oppression and mental health is first addressed by reporting on the colonization of bodies and minds through the removal of lay knowledge, psychiatrization and over-medication. In the second place, prescriptions and adhesions are addressed to understand which aspects of socio-educational action in mental health assumes the form of discourses and practices of an oppressive nature, and which Freirian pedagogical keys can be taken into consideration in order to reverse said condition. Thirdly, we describe the specificities of the myths, discourses and institutionalized practices that reproduce and maintain the oppression of psychiatrized subjects, as well as some conditions for their release; namely, the recovery of the word and the symbolic construction of one's own life stories. Finally, the experience of transformation that the international Hearing Voices movement is assuming is exposed as an example of liberation from biomedical oppression.

Palavras-chave: oppression; biomedical hegemony; suffering.

\section{ARQUEOLOGIA DA DOR. UM REENCONTRO COM PAULO FREIRE E IVAN ILLICH PARA APRENDER COM O SOFRIMENTO}

RESUMO: Este texto recupera ferramentas para uma pedagogia de libertação e promoção da intersubjetividade prejudicada no campo da saúde mental. Nossa leitura atualizada de Paulo Freire se articula em diálogo com as contribuições de Iván Illich e sua postura crítica com a patologização do sofrimento. Ambos os autores nos permitem fundamentar uma práxis no campo da saúde mental que denominamos arqueologia da dor. Para isso, em primeiro lugar, abordam-se as relações entre opressão e saúde mental, explicando a colonização de corpos e mentes por meio da subtração do saber leigo, da psiquiatria e da supermedicação. Em segundo lugar, as prescrições e a adesão são direcionadas para compreender quais aspectos do desempenho socioeducativo em saúde mental assumem a forma de discursos e práticas opressoras e quais chaves pedagógicas freirianas podem ser levadas em consideração para reverter essa condição. Terceiro, são apresentadas as especificidades dos mitos, discursos e práticas institucionalizadas que reproduzem e mantêm a opressão dos sujeitos psiquiatras, bem como algumas condições para sua libertação; a saber, o resgate da palavra e a construção simbólica das próprias histórias de vida. Por fim, a experiência de transformação que o movimento internacional Hearing Voices está assumindo é apresentada como um exemplo de libertação da opressão biomédica.

Keywords: opressão; hegemonia biomédica; sofrimento.

\section{INTRODUCCIÓN}

En su obra Pedagogía del oprimido, Paulo Freire (2012a) parte de que tanto la humanización como la deshumanización son posibilidades que se dan, dentro de la historia, en contextos reales y concretos. Sitúa ambas posibilidades en la raíz de la inconclusión de las personas que, sabiéndose inconclusas, buscan permanentemente saber más. Pero si tanto la humanización como la deshumanización son posibilidades históricas y no algo dado o 
inevitable, solo la primera responde a la verdadera vocación ontológica del ser humano: la de ser más. Por el contrario, la segunda, verificándose tanto en quienes son despojados y despojadas de su humanidad como en quienes deshumanizan, aparece en la historia como distorsión de ese ser más.

Consentir la opresión o comprometerse en la lucha por restaurar la humanidad allí donde se encuentra negada, son opciones posibles en la búsqueda permanente de las personas. Freire nos habla de esta dialéctica, de la permanencia y el cambio, mientras nos interpela como sujetos éticos en la historia para que asumamos nuestra responsabilidad, y optemos (FREIRE, 1997, 2012b).

La obra del autor brasileño representa la apuesta por una pedagogía cuya labor consiste en problematizar la opresión y hacer de ella y de sus causas el objeto de la reflexión y la práctica educativas. Conviene dejar claro que no se trata de una tarea asignada a una élite que, especializada, tenga por misión señalar el camino de la liberación a las pobres y deshumanizadas masas ignorantes. Al contrario, tiene como principales protagonistas precisamente a quienes viven la dominación en primera persona y a quienes con ellas y ellos se solidarizan en la lucha por la superación de la situación en que se hallan.

La pedagogía del oprimido busca la restauración de la intersubjetividad y su desarrollo debe llevarse a cabo con los oprimidos en el proceso de su organización. Dos son los momentos principales:

El primero, en el cual los oprimidos van desvelando el mundo de la opresión y se van comprometiendo, en la praxis, con su transformación, y el segundo, en que, una vez transformada la realidad opresora, esta pedagogía deja de ser del oprimido y pasa a ser la pedagogía de los hombres $^{3}$ en permanente proceso de liberación (FREIRE, 2012a, p. 43).

Freire nos proporciona herramientas para trabajar en la recuperación y promoción de la intersubjetividad dañada en el campo de la salud mental. A este respecto queremos intentar hacer una lectura actualizada de sus aportes y aplicada al campo del sufrimiento mental. La colonización y dominación de los sujetos psiquiatrizados por parte de la semántica biomédica, la fiscalización de la gestión política del sufrimiento, el mandato

\footnotetext{
${ }^{3}$ En la Pedagogía de la Esperanza, Freire (1992) revisa a partir de las críticas de numerosos grupos feministas en la década de los setenta, la utilización lenguaje sexista en sus primeras obras.
} 
neoliberal del capacitismo y la extensión normalizada de una conciencia ingenua que desactiva la agencia política son algunas de las razones principales de nuestra propuesta.

Con esta inquietud, hemos apostado por revisitar a Freire de la mano de Iván Illich. Los trabajos del pensador austríaco referidos al campo de la salud nos permiten una ampliación del diálogo entre ambos autores, esta vez, en lo que hace al sufrimiento. Entendido como mediador, el malestar emergerá como objeto a ser desvelado críticamente, en un intento por reintroducirlo como elemento clave en los procesos educativos y liberadores.

La extensión dialógica que nos proponemos politiza una vez más la educación evidenciando que esta no puede ser pensada desde el presupuesto de una neutralidad inexistente (FREIRE e ILLICH, 1975, MESQUIDA, 2007, COSTA, 2015). Tampoco lo será, por tanto, en el terreno de la salud mental.

\section{OPRESIÓN Y SALUD MENTAL}

Los rasgos estructurales que caracterizan el Modelo Médico Hegemónico de atención a la salud han sido sistematizados por autores como Menéndez (1984; 1988, 1992). Desde el punto de vista del antropólogo mexicano, los principales elementos que se hacen valer en su funcionamiento y reproducción son los siguientes:

Biologismo, individualismo, ahistoricidad, asociabilidad, mercantilismo, eficacia pragmática, asimetría, autoritarismo, participación subordinada y pasiva del paciente, exclusión del conocimiento del consumidor, legitimación jurídica, profesionalización formalizada, identificación con la racionalidad científica, tendencias inductivas al consumo médico (Menéndez, 1988, p. 452).

Cabe matizar, con relación al sufrimiento psíquico y particularmente a dolencias como la esquizofrenia, que la fuerza constitutiva de los aspectos citados descansa en una serie de hipótesis de signo biomédico ${ }^{4}$ que a duras penas encuentra respaldo en las evidencias científicas disponibles (READ, MOSHER Y BENTALL, 2006; GEEKIE Y READ, 2012). Sin embargo, institucionalizadas y a menudo incuestionadas, estas teorías con sus prácticas correspondientes son hoy predominantes en el ámbito de la salud mental. A su amparo se

\footnotetext{
${ }^{4}$ De entre ellas, destaca Martínez (1998) la teoría dopaminérgica, la estructural-cerebral, la vírica y la genética. Ideação. Revista do Centro de Educação, Letras e Saúde. v. 23, n¹, 2021. e-ISSN: 1982-3010.
} 
materializan unas relaciones de poder que, basadas en la jerarquía y unidireccionalidad del saber experto frente a los saberes populares (CORREA, 2010; MENÉNDEZ, 1992), han generado una suerte de iatrogénesis médica, cultural y social que no ha hecho sino añadir más sufrimiento al sufrimiento (ILLICH, 2006e; GOFFMAN, 1992).

Illich (2006d, 2006e) ha insistido en las nocivas repercusiones de este tipo de dinámicas denunciando, enérgicamente, que más daños a la salud causa la creencia de que la gente no puede afrontar las enfermedades sin las medicinas modernas y sin los médicos que imponen sus atenciones a los pacientes, de lo que su gestión autónoma. En otras palabras, el apoyarse cada vez más en la atención especializada agrega una dimensión psicológica a la situación de indefensión en que por lo general se encuentran las capas más desfavorecidas de la sociedad: la incapacidad de valerse por sí mismas. Es decir, confiar los cuidados al saber experto en exclusiva, las hace cada vez más dependientes de un tratamiento ulterior y "cada vez más incapaces de organizar sus propias vidas en torno a sus propias experiencias y recursos dentro de sus propias comunidades" (ILLICH, 2006d, p. 194). Ello permite entender una de las formas que toma la dominación en nuestras sociedades contemporáneas; a saber, la patologización del sufrimiento y malestar humano desactivando cualquier tipo de agencia relacionada con la autogestión del propio sufrimiento, incluida su politización. De este modo la colonización de los cuerpos y las mentes se produce y reproduce con la participación de algunos discursos psi que contribuyen activamente en la domesticación del carácter y la delegación en primera persona del poder sobre la vida.

A tenor de lo anterior y mientras las iniciativas de autogestión tanto individuales como colectivas en salud se han visto enormemente dificultadas, se ha hecho de la supuesta protección a las poblaciones -idealmente sumisas y dependientes- el gran negocio de profesiones como la médica (ILLICH, 2006e). De resultas, la creciente medicalización de la vida ha ido no solo despojando a las personas del poder sobre el manejo de su salud, sino que, a la vez, ha aumentado y justificado el control y la normativización de los cuerpos (ILLICH, 2006e, MENÉNDEZ, 1992).

En procesos semejantes es donde Freire (2012a) identifica la opresión, que adquiere en nuestras sociedades complejas numerosas formas y manifestaciones a menudo encubiertas. En particular, cualquier relación en que una persona impide a otra ser para sí, afirmarse, decir su palabra, decidir, actuar autónomamente, etc., es opresiva. De la misma 
manera, cuando alguien, en virtud de su poder, coarta a otro alguien en su búsqueda del ser más, lo deshumaniza y violenta condenándolo a ser menos. Desvelar críticamente las razones de la opresión, para transformarla, será una de las tareas principales de la investigación y la práctica educativas. Aquí, la perspectiva pedagógica freiriana coincide netamente con las aportaciones de Illich en la medida en que, la investigación radical para este último, busca detectar "las categorías de población más amenazadas y les ayuda a discernir la amenaza. Hace tomar conciencia a los individuos y grupos, hasta entonces divididos, de que sobre sus libertades fundamentales pesan las mismas amenazas" (2006d, p. 454).

Siguiendo con los planteamientos de ambos autores, algunas de las cuestiones que orientan el presente trabajo son: en un contexto de hegemonía biomédica ¿qué aspectos de la actuación socioeducativa en salud mental asumen la forma de discursos y prácticas de carácter opresivo?, ¿qué claves pedagógicas freirianas podemos tomar en consideración a efectos de revertir dicha condición?

\section{PRESCRIPCIONES Y ADHERENCIAS}

Uno de los primeros elementos que se advierte en las relaciones de opresión es lo que Freire (2012a) denomina prescripción. Esta consiste en la imposición de la opción de una conciencia a otra en un movimiento en el cual la primera niega el derecho fundamental de la segunda a ser ella misma, a ser auténticamente.

Conforme a la aproximación realizada por Illich (2006e) y específicamente en el terreno de la salud, la hegemonía biomédica habría logrado privar a quienes sufren de los cuidados que no están bajo las prescripciones técnicas correspondientes, imponiendo el consumo obligatorio de determinados servicios y atenciones. Provocados social y políticamente, algunos de los daños de la prescripción institucional se subsumen en lo que el autor denominó iatrogénesis social. De entre ellos destaca el modo en que:

La burocracia médica crea una salud enferma aumentando las tensiones, multiplicando la dependencia inhabilitante, generando nuevas y dolorosas necesidades, disminuyendo los niveles de tolerancia al malestar o al dolor, reduciendo el trato que la gente acostumbra a conceder al que sufre, $y$ aboliendo aun el derecho al cuidado de sí mismo (ILLICH, 2006e, p. 564). 
Conviene indicar que no solo son servicios y tratamientos lo que se prescribe en ámbitos como el de la salud mental. En un ejercicio que requiere de notables dosis de especulación, es también un tipo concreto de futuro, trágico, lo que junto a ellos se ofrece.

La tragedia se vincula al no lugar para todos los cuerpos improductivos, frágiles o rotos. La "debilidad" y la vulnerabilidad no tienen buena recepción en el mundo neoliberal y su negación forma parte de esta expulsión hacia la tragedia. La primacía del mercado prevalece y agrede a todo aquel que ostenta una incapacidad productiva (sea por prescripción o por elección). Sabemos con esto que los mecanismos de autoexplotación son las nuevas formas de sujeción y control social. Sacar el máximo rendimiento a la vida es el nuevo mandato social, aunque ello conlleve un rechazo a la propia vida real en cuanto frágil. Pero a tenor de Freire: lo que nos parece imposible de aceptar "es una democracia fundada en la ética del mercado que, perversa y dejándose llevar sólo por el lucro, imposibilita la misma democracia." Lo que nos "parece imposible es aceptar que no haya otro camino para las economías frágiles que acomodarse, pacientemente, al control y a los dictámenes del poder globalizador, poder ante el cual sólo podemos inclinarnos de forma fatalista, con los brazos cruzados, estupefactos o conformados." Lo que nos parece imposible "es callarnos ante esta expresión postmoderna de autoritarismo. (FREIRE, 2001, p. 59).

Como fuere, mediante la prescripción se genera lo que Freire llama adherencia de la conciencia oprimida a la conciencia opresora. Asumiendo como propias opciones y formas de ver el mundo que han sido elaboradas conforme a criterios ajenos, esta dependencia es utilizada por quien oprime para crear una dependencia cada vez mayor (FREIRE, 2012a). Alienadas, invadidas e incluso adaptadas, las personas oprimidas tienden a adoptar comportamientos e ideas sobre sí que son propios de seres negados. Albergando la sombra de quienes los oprimen, se convierten en seres duales o seres para otros:

Sufren una dualidad que se instala en la "interioridad" de su ser. Descubren que, al no ser libres, no llegan a ser auténticamente. Quieren ser, más temen ser. Son ellos y, al mismo tiempo, son el otro yo introyectado en ellos como conciencia opresora. Su lucha se da entre ser ellos mismos o ser duales. Entre expulsar o no al opresor desde "dentro" de sí. Entre desalienarse o mantenerse alienados. Entre seguir prescripciones o tener opciones. Entre ser espectadores o actores. Entre actuar o tener la ilusión de que actúan en la acción de los opresores. Entre decir la palabra o no tener voz, castrados en su poder de crear y recrear, en su poder de 
transformar el mundo. Este es el trágico dilema de los oprimidos, dilema que su pedagogía debe enfrentar (2012a, pp. 36, 37).

Al mismo tiempo que normalizan pautas de comportamiento que no son las suyas, se produce una autodesvalorización que refleja la visión que acerca de ellas y ellos tienen quienes oprimen. Esto se debe a que "de tanto oír de sí mismos que son incapaces, que no saben nada, que no pueden saber, que son enfermos, indolentes, que no producen, en virtud de todo esto terminan por convencerse de su 'incapacidad'" (FREIRE, 2012a, p. 51). Existe aquí una confusión entre el relato del self y el propio núcleo del self o verdad interior. Los sujetos introyectan la voz del opresor hasta el punto de imposibilitar la propia narrativa sobre sí mismos. Recuperar esta narrativa interior forma parte del ejercicio alfabetizador contemporáneo. Volver a contar(nos) y a narrar(nos) una verdad que fue sepultada bajo el peso de la narrativa hegemónica. Recuperar, en cierto modo, esta capacidad de construcción simbólica sobre las propias vidas. Freire cuenta este ejercicio de la mano de una persona en proceso de alfabetización en Río Grande do Norte:

Veo ahora, dijo, como si comenzase a liberarse de la falta de valía que se otorgaba a sí mismo, como zapatero, en su precario puesto de la esquina de la calle, "que mi oficio de remendar suelas de zapatos es también muy valioso. Con mi trabajo, a quien me trae un zapato roto, le devuelvo otro casi nuevo. Cuido los pies de las personas que, además, gastan menos poniendo mi suela en el zapato que si tuviesen que comprar otro nuevo. Tengo que luchar por la dignidad de mi trabajo y no avergonzarme por su causa (FREIRE, 2001, p. 61).

Dice Freire al respecto que la relectura que emprendió este joven mientras se alfabetizaba reconstruía un sí mismo. "En realidad aquel hombre se alfabetizaba en el sentido amplio y profundo que defiendo desde hace mucho tiempo. Él, que apenas leía mecánicamente oraciones y palabras, se consideraba promotor de tareas" (FREIRE, 2001, p. 61). Notemos el sentido amplio que Freire daba a la alfabetización, como lectura y (re)lectura de un sí mismo que se transforma y transforma el mundo en el que se inscribe. Esta idea amplia y compleja de lo que es la alfabetización, lectura y narrativa subjetiva y colectiva es lo que queremos destacar. Las personas psiquiatrizadas han sido leídas, interpretadas y descodificadas desde una semántica que no les es propia. Colonizadas en su totalidad deben poder volver a contarse con su lenguaje propio. Es decir, deben poder 
(re)alfabetizar sus propias historias de vida para alejarse de la sumisión biomédica. Pero la hegemonía opera de modo insidioso, persistente, silencioso y cotidiano. Distintos mecanismos de opresión explican la dificultad que encuentran los sujetos para liberarse e interpretar su diferencia desde otros lugares.

Repartiendo faltas, dependencias e innumerables sospechas, el estigma de la enfermedad mental opera, por añadidura, bloqueando denuncias y alternativas. Nos recuerda Illich que, achacando degradación a la identidad de una persona se la marca de forma indeleble con todo un elenco de atribuciones que acaban interiorizándose. Añade el autor, para que nada falte, que en un contexto de racionalidad hegemónica "la sospecha profesional basta por sí sola para legitimar el estigma aunque la condición sospechada nunca existiera" (ILLICH, 2006e, p. 607).

\section{MITOS, DISCURSOS Y PRÁCTICAS INSTITUCIONALIZADOS}

Freire (2012a) ha insistido en que, dentro de la lógica de la dominación, quienes oprimen se esfuerzan por impedir a las personas el desarrollo de su condición de admiradoras del mundo. En otras palabras, tratan por todos los medios de que no se vean convertidas en objetos y busquen superar tal condición. Dado que no siempre lo consiguen, se impone la necesidad de mitificar el mundo, haciendo creer a quienes son objeto de atención que se les ayuda.

Así, pues, quienes oprimen despliegan toda «una serie de recursos mediante los cuales proponen a la 'admiración' de las masas conquistadas y oprimidas un mundo falso. Un mundo de engaños que, alienándolas más aún, las mantenga en un estado de pasividad frente a él» (FREIRE, 2012a, p. 142). Aprendida de este modo su indefensión y nula capacidad para el cambio, las y los oprimidos «hablan de sí mismos como los que no saben y del profesional como quien sabe y a quien deben escuchar» (FREIRE, 2012a, p. 51). En el marco de las fórmulas jerárquicas y autoritarias dominantes, el carácter antidialógico y bancario en la actuación profesional se abre paso «a través de 'comunicados', de 'depósitos', de aquellos mitos indispensables para la conservación del statu quo» (FREIRE, 2012a, p. 142). 
Importa destacar que el modelo biomédico es también hegemónico en la formación de quienes trabajan en salud mental. Esto conlleva, sin duda, "una cosmovisión, unos valores y unas formas de conducirse que no necesariamente coinciden con las de quienes buscan ayuda profesional, con las consecuencias negativas que estas disonancias provocan en el proceso terapéutico» (GONZÁLEZ y COMELLES, 2000, p. 10). La divergencia correspondiente suele resolverse, las más de las veces, en favor de mitos como la incapacidad asociada a las dolencias, la idea de su cronicidad y origen biológico, que los psicofármacos son imprescindibles, que resultan más eficaces que el placebo o que sus efectos terapéuticos compensan aquellos adversos. Entre otras, las creencias citadas pueblan hoy en día un panorama atencional lleno de "anécdotas, folclore y supersticiones que se quieren hacer pasar por conocimientos científicos" (ROSS y READ, 2006).

Para quien sufre, todo este conjunto mitológico deviene religión malsana al desplegarse en "rituales que enfocan toda la expectativa del enfermo en la ciencia y sus funcionarios, en vez de darle valor para buscar una interpretación poética a su dificultad o para encontrar un ejemplo admirable en alguna persona - vecina o muerta hace tiempoque aprendió a sufrir" (ILLICH, 2006e, p. 627). Es la historia de un empeño, prometeico, por forjar instituciones con que afrontar cualquier mal humano. Es, en definitiva, la historia de una esperanza en la gestión autónoma que declina en favor de expectativas crecientes puestas en remedios prediseñados e institucionalmente programados (ILLICH, 2006b).

Conviene diferenciar, aquí, dos caras del funcionamiento institucional dentro de los circuitos asistenciales. La primera la aporta la perspectiva, ya comentada, según la cual las instituciones operan como estructuras dominadoras que impiden cualquier forma de autogobierno. La segunda, complementaria, la proporciona la idea de su funcionamiento como agencias formadoras de futuros invasores (ILLICH, 2006d, FREIRE, 2012a).

Acerca de este segundo sentido, considera Freire (2012a) que, al margen de la especialidad que tengan las y los profesionales que sirven a los intereses de la institución, a ellos compete transferir su visión del mundo, conocimientos y técnicas al pueblo ignorante e incapaz, desatendiendo la percepción de este al respecto de su realidad. De aquí se desprende que, aun cuando en un cierto momento de su experiencia existencial, las y los invadidos por el discurso dominante empiezan a cuestionarlo, quienes invaden se refieran a ellos como «inferiores», «enfermos» o «desagradecidos». La razón última descansa, para el 
autor, en el hecho de que «indiscutiblemente, los profesionales, con o sin formación universitaria, cualquiera que sea su especialidad, son hombres que estuvieron bajo la 'sobredeterminación' de una cultura de dominación, que los constituyó como seres duales» (FREIRE, 2012a, p. 161). Atendiendo a lo anterior, Illich (2006d, p. 503) señala el modo en que el círculo se cierra cuando afirma que «el lenguaje en que se percibe a sí mismo el ciudadano, su percepción de los derechos y libertades, y su conciencia de las necesidades, derivan de la hegemonía profesional".

Para subvertir estas inercias será, pues, necesaria la toma de conciencia de una serie de límites que se imponen en las relaciones de dominación.

\section{LA CONCIENCIA DE LOS LÍMITES}

Recuerda Freire $(2012 a, p, 53)$ que «hasta el momento en que los oprimidos no toman conciencia de las razones de su estado de opresión, 'aceptan' fatalistamente su explotación», manteniendo intacto el estado de cosas. En este contexto, inmovilizador, la pedagogía del oprimido se presenta como una herramienta para el desvelamiento crítico de la realidad que puede y debe ser modificada.

Con tal propósito, resulta indispensable que los grupos oprimidos no conciban la situación en que se hallan como algo estático o inmutable. Es preciso, antes bien, que reconozcan en el límite que la opresión les impone un desafío que movilice su acción. Por decirlo con otras palabras, "no son las `situaciones límite', en sí mismas, generadoras de un clima de desesperanza, sino la percepción que los hombres tengan de ellas en un momento histórico determinado, como un freno para ellos, como algo que ellos no pueden superar» (2012a, p. 96). Hay que destacar que, cuando en la acción misma se instaura la percepción crítica por medio del análisis político serio y correcto, se abre la posibilidad de superación de las "situaciones límite" y se descubren las razones que alientan la esperanza y el cambio (FREIRE, 1992).

En continuidad con los trabajos de Freire e Illich, diferentes autores han reclamado la necesidad de recuperar esta idea de situaciones límite (RIECHMANN, 2007, LATOUCHE, 2009, TAIBO, 2020). Su superación reclama no solo hacer algunas cosas, sino también no hacer o dejar de hacer, otras. Así entendido, el límite deviene elemento constitutivo de la 
libertad en un doble sentido: pone freno a la explotación, por un lado, mientras detiene la complicidad del sujeto mediante la sumisión y autoexplotación, por otro.

Frente a la óptica determinista de la historia que niega cualquier potencial de transformación al sujeto, Freire opone la concepción de la historia como posibilidad. Desde esta perspectiva, que correspondería a profesionales progresistas de no importa qué disciplina, se sitúa en el centro la experiencia de las personas y se les reconoce su papel en la conducción y transformación de sus vidas. En este escenario, las condiciones para la utopía realizable (ILLICH, 2006d) o el inédito viable (FREIRE, 1992) implican asumir «la tensión entre la denuncia de un presente que se hace cada vez más intolerable y el anuncio de un futuro por crear, por construir política, estética y éticamente entre todos, mujeres y hombres» (FREIRE, 1992, p. 116).

Sobre esto, nótese como en nuestro momento contemporáneo la desilusión, la parálisis y la sensación fatalista son inconmensurables. Por ello es más necesario que nunca volver a creer en utopías y levantar campos de lo posible allá donde nos encontremos. Pero para levantar campos también necesitamos diseños de un mañana mejor. Como nos recuerda Freire que sea posible no significa que sea fácil. De este modo "una de las tareas primordiales de la pedagogía crítica radical y liberadora es promover la legitimidad del sueño ético-político de la superación de la realidad injusta" (FREIRE, 2001, p. 53).

De la problematización de las situaciones de opresión y del reconocimiento crítico de sus límites y razones (materiales, sociales, políticas, económicas e ideológicas), emana el poder y la esperanza para emprender, como sujetos, el proceso permanente de liberación. Lo que supone, según Freire (1992), la necesidad de correr riesgos sin los que no es posible vivir, ni mucho menos existir. Es decir, aprender a abordarlos es, sin duda, tarea educativa.

Pero como quiera que los riesgos son parte indisociable de la libertad, ya el "orden" político se ha encargado de someter y mantener, pasiva y "democráticamente", a cada cual en su lugar (ILLICH, 2006a). No sorprende, por tanto, que no haya tolerado una educación orientada a despertar la conciencia de los grupos oprimidos que "promueva su originalidad y los impulse al riesgo. Dar eso a los adultos es exhortarlos a liberarse de los tabúes y a destronar los ídolos que los defensores del status quo tan celosamente custodian" (ILLICH, 2006a, p. 149). 
Aun con todo, conviene insistir en que la libertad, que es lo que aquí está en juego, llama a afrontar los riesgos de decidir y romper con el orden establecido, a conjurar el miedo de expulsar la opresión y, en fin, a llenar su vacío con contenidos nuevos: los de la autonomía y la responsabilidad (FREIRE, 2012a, 2012b).

En el campo de la salud mental, romper supone recuperar la propia voz narrativa sobre el dolor, introduciendo un quiebro al nivel de la participación de los grupos en el sostenimiento y reproducción de la hegemonía (MENÉNDEZ, 1992). De otro modo, los efectos deshumanizantes de la Némesis médica ${ }^{5}$ sólo pueden revertirse a condición de que las personas legas recobren su voluntad de autoasistencia mutua e impongan límites al monopolio profesional y sus mistificaciones (ILLICH, 2006e).

\section{LA MEMORIA DE LAS TRAMAS Y LA ARQUEOLOGÍA DEL DOLOR}

Una cuestión clave a la hora de insertarse críticamente en la realidad y superar la opresión, tiene que ver con la palabra y con el derecho primordial de decirla que tenemos todas las personas y no tan solo una élite privilegiada. La palabra resulta inseparable de la acción y de la reflexión con que construimos el mundo. Pronunciar la palabra, en consecuencia, no es mero verbalismo desconectado de la acción, sino que es acto, es reflexión y es transformación del mundo. Freire la describe de la siguiente manera:

La búsqueda por encontrar los elementos constitutivos de la palabra nos lleva a sorprender en ella dos dimensiones - acción y reflexión- en tal forma solidarias, y en una interacción tan radical que, sacrificada, aunque en parte una de ellas, se resiente inmediatamente la otra. No hay palabra verdadera que no sea una unión inquebrantable entre acción y reflexión y, por ende, que no sea praxis. De ahí que decir la palabra verdadera sea transformar el mundo» (FREIRE, 2012a, p. 83).

Señala Arendt (2005, p. 207) que con la palabra y con la acción «nos insertamos en el mundo humano, y esta inserción es como un segundo nacimiento», en virtud del que tomamos la iniciativa y aparecemos entre las y los otros. Para la autora, no es el comienzo

\footnotetext{
5 Illich acude al término de Némesis para denominar la espiral autorreforzante de retroalimentación institucional que opera en el campo de la medicina. Con dicho concepto apela a la venganza divina que recaía sobre quienes, en su condición de mortales, usurpan los privilegios que los dioses guardaban celosamente para sí.
} 
de algo, sino de alguien, en un parto doloroso donde quien nace es el ser humano liberándose descrito por Illich y Freire.

No obstante, conviene en este punto recordar que nadie libera a nadie ni nadie se libera solo. Las personas se liberan, antes bien, en el encuentro y en la colaboración, transformando el soporte natural en mundo y nuestra vida en existencia (FREIRE, 1997). Por ello el diálogo se impone como el camino mediante el que las personas ganan significación en cuanto tales.

Y es que no hay personas sin mundo, dirá Freire, sin realidad que medie entre ellas. Como todo lo que está en medio, une y separa al mismo tiempo, constituyendo la esfera de los asuntos humanos «donde existimos primordialmente como seres que actúan y hablan» (ARENDT, 2005, p. 211). Es a esta esfera, a través de la interacción y en la intercomunicación entre las personas, adonde debe dirigirse la praxis y la lucha por la liberación. A tal efecto, lo interesante es comprender las tramas y los procesos en que ocurren o se dan las experiencias que vivimos y compartimos, para incidir en ellos a través de la acción y la reflexión. En palabras de Freire:

\begin{abstract}
Un acontecimiento, un hecho, un acto, una canción, un gesto, un poema, un libro están siempre involucrados en densas tramas, tocados por múltiples razones de ser, algunas de las cuales están más cerca de lo ocurrido o de lo creado, mientras que otras son más visibles en cuanto razón de ser. Por eso a mí me interesó siempre mucho más la comprensión del proceso en qué y cómo las cosas se dan que el producto en sí» (FREIRE, 1992, pp. 34, 35).
\end{abstract}

La liberación, que es un proceso de búsqueda permanente, ocurre en el encuentro y en el diálogo entre las personas para transformar las sociedades que no son, sino que están siendo, lo que de ellas hacemos en la historia (FREIRE, 1997). La objetividad y la subjetividad se dan simultáneamente, no pudiendo pensarse por separado: «hablar, comprender, comunicar y comunicarse son quehaceres solidarios, a un tiempo causa y efecto de la presencia de lo humano, de la invención del mundo» (FREIRE, 1997, p. 22) como punto de partida del actuar concertadamente para el cambio de la realidad.

Señala el autor la importancia de rastrear la memoria de las tramas que atraviesan nuestra vida, las cuales contienen saberes y experiencias desde los que podemos comprender y subvertir mejor las situaciones de opresión que vivimos. En su opinión, es en 
el juego de las tramas donde la vida adquiere su sentido: «Llegué al exilio — nos dice- y a la memoria de tantas tramas que traía en el cuerpo añadí la marca de nuevos hechos, nuevos saberes que se constituían entonces en nuevas tramas» (FREIRE, 1992, p. 27). Nos habla de fragmentos de tiempo que se alargan en la composición de tramas mayores y cuyo parentesco a veces no percibimos, perdiendo «la posibilidad de 'soldar' conocimientos desligados $\mathrm{y}$, al hacerlo, iluminar con los segundos la precaria claridad de los primeros» (p. 35).

Según la experiencia del pedagogo brasileño, esto es lo que sucede con el sufrimiento, que es consecuencia y parte indisociable de la opresión. Su propuesta consiste en tratar de situarlo en el cuadro general en el que se da. Es decir, propone diferenciar los elementos que lo rodean y forman parte de él para, con esos materiales, convertirlo en el objeto de nuestra curiosidad. Es decir (re)aprender el sufrimiento y con ello recuperar la legitimidad que se tiene sobre el propio cuerpo hasta entonces fiscalizado por narrativas biomédicas. Este ejercicio de (re)tejido de las costuras y las tramas que configuran las biografías es lo que hemos llamado arqueología del dolor. Excavar para descubrir elementos sepultados en las capas de la piel. (Re)escribir la propia historia con significantes nuevos o recuperados del olvido. Existe en este último punto una (re)alfabetización permanente en cuanto a terminología biomédica se refiere. Esto es, autorizarse a producir neologismos que denuncian situaciones de opresión a la par que abren nuevas cosmovisiones.

Tan lejos de galimatías burocráticos y terminológicos impuestos, como del papel de sujetos pacientes o desviados, la tarea consiste en recuperar la memoria biográfica y la expresión de los cuerpos dolientes ante el designio biomédico de abolir la necesidad de un verdadero arte de sufrir (ILLICH, 2006e).

La cuestión radica, pues, en tomar distancia del malestar para aprehender su razón de ser, arrojando luz sobre los hechos y los actos en que se genera. Es decir, iluminando su dimensión social e interrogándose sobre su carácter comunicable o incomunicable y politizador. Sin embargo, si admitimos que cada vez con mayor frecuencia "la persona que sufre un dolor va quedándose con menos y menos contexto social que pueda darle significación a la experiencia que lo abruma" (ILLICH, 2006e, p. 646), entonces encontrarse con las y los otros resulta imprescindible (FREIRE, 1997) en esta tarea de construcción de sentido. 
De ahí se desprende la importancia de generar espacios colectivos y horizontales donde articular un tipo de crítica radical a través de la que cuestionar "las asunciones e instituciones que se han convertido en ídolos, en nombre del sentido común, la lógica y lo que se supone que es natural" (FROMM, 2006, p. 47).

Desde esta perspectiva, para realizar la arqueología del dolor es necesario educar la esperanza en que las cosas pueden ser de otra manera, trabajando las relaciones interpersonales y la voluntad del cambio sin esperar, no obstante, que la transformación como por generación espontánea simplemente ocurra. Freire insiste en que al desnudar la trama en que los hechos se dan, las personas todavía no se liberan de la opresión; «sin embargo, al desnudarla dan un paso para superarla, siempre que se empeñen en la lucha política por la transformación de las condiciones concretas en que se da la opresión» (FREIRE, 1992, p. 50). Cuando acontece esto hablamos de espacios en salud capaces de habilitar redes de sostén colectivas que transforman, a su vez, la propia percepción del sufrimiento.

Porque las tramas, para Freire, nos atraviesan transversal y longitudinalmente:

Cargamos con nosotros la memoria de muchas tramas, el cuerpo mojado de nuestra historia, de nuestra cultura; la memoria, a veces difusa, a veces nítida, clara, de calles de la infancia, de la adolescencia; el recuerdo de algo distante que de repente se destaca nítido frente a nosotros, en nosotros, un gesto tímido, la mano que se estrechó, la sonrisa que se perdió en un tiempo de incomprensiones, una frase, una pura frase posiblemente ya olvidada por quien la dijo. Una palabra por mucho tiempo ensayada y jamás dicha, ahogada siempre en la inhibición, en el miedo de ser rechazado que, al implicar falta de confianza en nosotros mismos, significa también la negación del riesgo» (1992, p. 50).

\section{EMPRENDER TRANSFORMACIONES EN SALUD MENTAL: EL CASO DE HEARING VOICES}

Pero la opresión, al constituirse en el mundo como un «mecanismo de absorción de los que en ella se encuentran, funciona como una fuerza de inmersión de las conciencias» (FREIRE, 2012a, p. 39) que dificulta enormemente el proceso de darse cuenta de su concreción y sus causas. En tales circunstancias, la toma de conciencia se produce en un movimiento de emersión de la realidad en la que las personas se hallan inmersas para, distanciándose de ella, verla como una realidad objetivo-problemática susceptible de ser 
modificada. Resulta necesario, por tanto, admirar la situación concreta para insertarse críticamente $^{6}$ en ella y transformarla. Según Freire, «la verdadera presencia en el mundo no es la de quien se adapta a él, sino la de quien se inserta en él. Es la posición de quien lucha para no ser tan solo un objeto, sino también un sujeto en la historia» (2012a, p. 53).

Illich (2006d, p. 394) se pregunta también acerca de cómo romper el círculo opresivo. En su opinión, resulta fundamental:

\begin{abstract}
hacerse la pregunta: ¿quién me encadena, quién me habitúa a sus drogas? Hacerse la pregunta es ya responderla. Es liberarse de la opresión del sinsentido y de la falta, reconociendo cada uno su propia capacidad de aprender, de moverse, de descuidarse, de hacerse entender y de comprender. Esta liberación es obligatoriamente instantánea, puesto que no hay término medio entre la inconsciencia y el despertar.
\end{abstract}

Dicho proceso de darse cuenta supone el punto de partida de la inserción crítica y exige lo que Freire denomina praxis, que «es reflexión y acción de los hombres sobre el mundo para transformarlo. Sin ella es imposible la superación de la contradicción opresoroprimido» (2012a, p. 40).

Aunque someramente, en lo que sigue revisamos una experiencia colectiva llevada a la práctica en el terreno de la salud mental, que materializa el proceso de inserción crítica para la transformación que venimos caracterizando. Se trata de la lucha del Movimiento Internacional de Escuchadoras de Voces o Hearing Voices.

Indiquemos, antes de nada, que diversas investigaciones han puesto de manifiesto la relevancia de los aportes que al ámbito de la salud mental han realizado en los últimos años los movimientos de personas afectadas por problemáticas de sufrimiento psíquico (LEHMANN, 2013; CHAMBERLIN, 2006; GEEKIE y READ, 2012; ORTIZ, 2013; COOK et al., 2015). Estos comprenden desde grupos y organizaciones locales hasta nacionales e internacionales -con sus redes-, capitaneados y controlados por personas usuarias, exusuarias y supervivientes de la psiquiatría. Con frecuencia se encuentran hoy en primera línea a la hora de desarrollar abordajes innovadores de autoatención, "bien prestando servicios independientes, o bien contribuyendo en los servicios de salud mental tradicionales" (COOK et al., 2015, p. 84). Mientras su objetivo principal consiste en provocar

\footnotetext{
${ }^{6}$ La cuestión de la criticidad representa la superación en Pedagogía del oprimido (2012) de la concepción de la concienciación esbozada en La educación como práctica de la libertad (1976).
} 
un cambio radical en el sistema de atención, su praxis descansa en los principios de autogestión y apoyo mutuo, en la simetría la reciprocidad de saberes, así como en la libertad de elección (ORTIZ, 2013, ERRO, 2016).

De hecho, para Lehman (2013), una parte significativa de estos movimientos mantiene en la actualidad una actitud combativa que se manifiesta en aspectos tales como: la unión, la lucha contra la vulneración por parte de la psiquiatría de los derechos humanos, el abordaje colectivo de las condiciones de vida de sus miembros, la auto-organización y la autoayuda, la liberación de las influencias psiquiátricas, la búsqueda compartida del sentido de la locura, el debate crítico y simétrico con expertos, la minimización del poder al interior de los grupos y la resistencia al control ajeno.

Aunque no todos los grupos que se pueden encuadrar dentro del movimiento de personas usuarias, ex-usuarias y supervivientes del sistema de salud mental responden a esta lógica reivindicativa, todos coinciden en resaltar el alto valor del conocimiento de sus participantes y la importancia de la ayuda mutua o el apoyo entre pares (GEEKIE y READ, 2012; LEHMAN, 2013; ERRO, 2016).

Si bien a partir de la última década del siglo $X X$ estos grupos de autoayuda han proliferado de forma espectacular, todavía siguen representando una expresión minoritaria como para constituirse en una verdadera alternativa al sistema de atención hegemónico (CHAMBERLIN, 2006).

Tal y como avanzamos, un ejemplo de iniciativa radical y combativa en salud mental lo conforma la Red Internacional de Escuchadoras de Voces, o Hearing Voices ${ }^{7}$. Integrada fundamentalmente por personas usuarias, ex-usuarias y supervivientes de la psiquiatría, esta red internacional ha podido extender, a partir de la lucha de sus participantes, una nueva cultura convivencial en torno al sufrimiento mental. Experiencias comúnmente denominadas como síntomas psiquiátricos, son entendidas como reacciones humanas comprensibles a situaciones vitales complejas cuyo significado permite orientar el cambio y la recuperación (CORSTENS et. al., 2014).

La manera en que se organiza el movimiento es a través de grupos pequeños a nivel local, que comparten filosofía y objetivos. Sus miembros defienden una visión crítica con relación al modelo médico hegemónico y promueven un tipo de acción política que se aleja

\footnotetext{
${ }^{7}$ Para más información, ver: https://www.hearing-voices.org/ Ideação. Revista do Centro de Educação, Letras e Saúde. v. 23, n¹, 2021. e-ISSN: 1982-3010.
} 
de la atención clínica jerarquizada, de la imposición de saberes o de las formas más comunes de asistencialismo. De entre los principales valores que asumen, se encuentran los siguientes (CORSTENS et. al., 2014):

1. Las experiencias comúnmente asociadas a la psicosis se conceptualizan no como fenómenos anormales, aberrantes o producto de una enfermedad del cerebro, sino como respuestas interpretables en función de las circunstancias sociales, emocionales y/o interpersonales.

2. Se aceptan y validan diversas explicaciones para experiencias como la escucha de voces, las alucinaciones o los delirios, admitiendo y respetando variados significados. Es decir, se ponen en contexto biográfico estos fenómenos tradicionalmente estigmatizados y por ello ocultados. Se comparten las experiencias y se (re)significan sus sentidos culturales o simbólicos.

3. Se anima a las personas participantes a que se apropien de su experiencia y la definan en sus propios términos. En este sentido, se advierte del potencial incapacitante y colonizador que la narrativa biomédica y sus prescripciones tienen sobre otros marcos comprensivos y de actuación posibles.

4. Se consideran las experiencias inusuales como susceptibles de ser interpretadas y comprendidas en el contexto de los acontecimientos vitales y las narrativas interpersonales.

5. Frente a la extendida pretensión de anular experiencias como la escucha de voces, se estima que su aceptación y gestión puede realizarse con éxito honrando la realidad subjetiva de las y los protagonistas.

6. El apoyo mutuo supone un pilar fundamental en el impulso de contextos donde las personas puedan socializar, dar sentido y afrontar sus experiencias de opresión y malestar.

El cambio de valores indicado se asienta en una tradición de lucha que pone en el centro de sus actuaciones la producción y circulación de saberes con base en la experiencia personal. Considerados como expertos, dichos saberes se reivindican como materiales vivos de la cultura, cuya movilización entre iguales supone el principal recurso del que disponen las personas para el enfrentamiento del sufrimiento psíquico.

Los desplazamientos en las posiciones de producción del saber han conseguido reunir no solo a numerosas personas que viven o han vivido problemáticas relativas a su salud mental a lo largo de todo el mundo. Cada vez más familiares y profesionales se han acercado 
a las propuestas del movimiento, materializando y consolidando profundos cambios culturales en materia de locura.

Cabe matizar, no obstante, que la trayectoria de movimientos sociales como este no se encuentra exenta de eventuales contradicciones y conflictos en su interior. Así, por ejemplo y en continuidad con sus raíces radicales, en el seno de Hearing Voices convive la disyuntiva de si enfocar los esfuerzos al desarrollo de prácticas reformistas dentro de los diferentes sistemas de salud mental, o articular las alternativas por fuera de lo establecido. La tensión entre ambas líneas estratégicas se percibe, también, en el dilema acerca de si centrar el foco de la lucha y los esfuerzos principalmente en la atención individualizada, o combinarlos con el enfrentamiento de las problemáticas sociales, políticas y económicas, que se considera están en el origen del sufrimiento mental (CORSTENS et al., 2014). Emerge aquí la vieja controversia apuntada por Freire (1997), que diferencia entre la política asistencialista de aquella otra que asiste sin asistencializar: si la primera sugiere que el problema de las y los desheredados se sitúa en sus carencias o dificultades, la segunda se corresponde con la tarea político-educativa que subraya la importancia de lo social, de lo económico y del poder en la producción de la opresión y el malestar.

\section{CONSIDERACIONES FINALES}

Como fuere, Hearing Voices representa una apuesta actual orientada a la construcción de redes convivenciales (ILLICH, 2006) desde las que construir formas relacionales diferentes a partir de las que enfrentar el malestar. Asentadas en verdaderos círculos de cultura (FREIRE, 1986), estas se encaminan a la restauración de la intersubjetividad y la promoción, desde la base, de iniciativas autogestionadas y horizontales con que contestar la hegemonía.

A través de la generación de espacios en salud, la arqueología del dolor y la recuperación de la propia voz narrativa adquieren un papel relevante en los procesos de cambio vividos por los miembros del movimiento. En este sentido, por lo demás, nos recuerdan que "no existe el pensar acertado fuera de una práctica testimonial que lo refuerza en lugar de desdecirlo" (FREIRE, 2012b, p. 36). Así, validando y afirmando sus 
relatos a través su testimonio, quienes se encuentran en una situación desfavorable y socialmente deslegitimada, responden políticamente a tal situación.

Se trata, en último término, de un tipo de lucha que pone en el centro el empoderamiento individual, pero reconociendo a la vez lo imprescindible de incardinarlo en una estrategia colectiva para la transformación radical de la sociedad. Es decir, la libertad experimentada en lo personal es empleada para ayudar a otras personas a liberarse, también, en un movimiento conjunto por el cambio global (FREIRE, 1987) que, sin duda, se sitúa en la estela de las principales propuestas realizadas por Freire e Illich (MESQUIDA, 2007).

\section{REFERÊNCIAS}

ARENDT H. La condición humana. Barcelona: Paidós Surcos, 2005.

CHAMBERLIN J. (2006). Servicios dirigidos por los usuarios. En: READ J, MOSHER L y BENTALL R (Edits.), Modelos de locura. Barcelona: Herder Editorial, 2006b, p. 343-351.

COOKE A, BASSET T, BENTALL R, BOYLE M, CUPITT C, DILLON J, . . PETERS E. Comprender la psicosis y la esquizofrenia. ¿Por qué a veces las personas oyen voces, creen cosas que a otros les parecen extrañas, o parecen estar fuera de la realidad, y qué es lo que puede ayudarles? Sociedad Británica de Psicología Clínica, Sección de Psicología Clínica. Canterbury: Canterbury Christ Church University, 2015.

CORREA M. Radio nikosia: La rebelión de los saberes profanos. Otras prácticas, otros territorios para la locura. Universitat Rovira i Virgili. Departament d'Antropologia, Filosofia i Treball Social: 2010.

CORSTENS D, LONGDEN E, MCCARTHY-JONES S, WADDINGHAM R y THOMAS N. Perspectivas emergentes del movimiento de escuhadores de voces: implicaciones para la investigación y la práctica, 2016. Disponible en: https://entrevoces.org/es ES/materiales/perspectivasemergentes-del-movimiento-de-escuchadores-de-voces-implicaciones-para-la-investigaciony-la-practica-vvaa/

COSTA G. A polêmica Paulo Freire e Ivan Illich: notas sobre educaçao e transformaçao. Revista Sul-Americana de Filosofia e Educaçao-RESAFE, N, 24, 2015, p. 102-120.

ERRO J. Saldremos de esta. Guía de salud mental para el entorno de la persona en crisis. Granada: Biblioteca Social Hnos. Quero, 2016.

FREIRE P. La educación como práctica de la libertad. Madrid: Siglo XXI, 1976. 
FREIRE P. ¿Extensión o comunicación? La concientización en el medio rural. Montevideo: Siglo XXI editores, 1984.

FREIRE P. Pedagogía de la esperanza: un reencuentro con la Pedagogía del oprimido. México: Siglo XXI, 1992.

FREIRE P. A la sombra de este árbol. Barcelona: El Roure, 1997.

FREIRE P. Política e Educação. Sao Paulo: Cortez, 2001.

FREIRE.P. Pedagogía de la indignación. Madrid: Ediciones Morata, 2001.

FREIRE P. Cartas a quien pretende enseñar. Buenos Aires: Siglo XXI, 2004.

FREIRE P. Pedagogía del Oprimido. Madrid: Siglo XXI, 2012a.

FREIRE P. Pedagogía de la autonomía: saberes necesarios para la práctica educativa. México: Siglo XXI, 2012b.

FREIRE P e ILLICH I. Diálogo. Análisis crítico de la "desescolarización" y "concientización" en la coyuntura actual del sistema educativo. Buenos Aires: Ediciones Búsqueda, 1975.

FROMM E. Introducción. En: Borremans V y Sicilia J (Edits.), Iván Illich. Obras reunidas I. México: Fondo de Cultura Económica, 2006, p. 47-50.

GEEKIE J y READ J. El sentido de la locura. Barcelona: Herder, 2012.

GOFFMAN E. Internados. Ensayos sobre la situación social de los enfermos mentales. Buenos Aires: Amorrortu Editores, 1992.

GONZÁLEZ E y COMELLES JM. Psiquiatría Transcultural. Madrid: Asociación Española de Neuropsiquiatría, 2000.

ILLICH I. Alternativas. En: Borremans V y Sicilia J (Edits.), Iván Illich. Obras reunidas I. México: Fondo de Cultura Económica, 2006a, p. 51-188.

ILLICH I. La sociedad desescolarizada. En: Borremans V y Sicilia J (Edits.), Iván Illich. Obras reunidas I. México: Fondo de Cultura Económica, 2006b, p. 189-326.

ILLICH I. Energía y equidad. En: Borremans V y Sicilia J (Edits.), Iván Illich. Obras reunidas I. México: Fondo de Cultura Económica, 2006c, p. 327-368.

ILLICH I. La convivencialidad. En: Borremans V y Sicilia J (Edits.), Iván Illich. Obras reunidas I. México: Fondo de Cultura Económica, 2006d, p. 369-532.

ILLICH I. Némesis Médica. En: Borremans V y Sicilia J (Edits.), Iván Illich. Obras reunidas I. México: Fondo de Cultura Económica, 2006e, p. 533-760. 
LATOUCHE S. La apuesta por el decrecimiento. ¿Cómo salir del imaginario dominante? Barcelona: Icaria Antrazyt, 2006.

LEHMANN P. Alternativas a la Psiquiatría. Revisata de la Asociación Española de Neuropsiquiatría, 33 (117), 2013, p. 137-150.

MENÉNDEZ E. El modelo médico hegemónico: transacciones y alternativas hacia una fundamentación teórica del modelo de autoatención en salud. Arxiu d'etnografía de Catalunya, no 3, 1984, p. 84-119.

MENÉNDEZ, E. (1988). Modelo médico hegemónico y atención primaria. Buenos Aires: Segundas Jornadas de Atención Primaria de la Salud, 1988, p. 451-464.

MENÉNDEZ, E. (1992). Hacia una práctica médica alternativa. Hegemonía y autoatención (gestión) en salud. En: Campos R (Ed.), Antropología médica en México 1. México: Instituto Mora-UAM, 1992, p. 97-113.

MESQUIDA P. O diálogo de Illich e Freire em torno da educaçao para uma nova sociedade. Contrapontos, V7, N3, 2007, p. 549-563.

ORTIZ A. Hacia una psiquiatría crítica. Madrid: Grupo 5, 2013.

READ J, MOSHER L, BENTALL R. La "esquizofrenia" no es una enfermedad. En: READ J, MOSHER L y BENTALL R (Edits.), Modelos de locura. Barcelona: Herder Editorial, 2006, p. 310.

RIECHMANN J. Oikos y Jaikus. Reflexiones sobre la crisis ecosocial. En: Linz M, Riechmann J, y Sempere J, Vivir (bien) con menos. Barcelona: Icaria Editorial, 2007, p. 69-119.

ROSS C y READ J. Los fármacos antipsicóticos: mitos y realidades. En: READ J, MOSHER L y BENTALL R (Edits.), Modelos de locura. Barcelona: Herder Editorial, 2006, p. 123-140.

TAIBO C. Colapso. Capitalismo terminal, transición ecosocial, ecofascismo. Madrid: Los libros de la catarata, 2020.

Recebido em 11 de abril de 2020.

Aprovado em 07 de agosto de 2020.

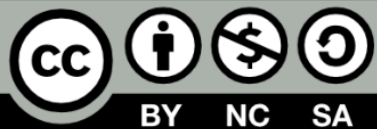

